Int. J. Dev. Biol. 60: 263-270 (2016)

doi: $10.1387 / \mathrm{ijdb} .160186 \mathrm{gm}$

\title{
Ubiquitin-mediated proteolysis in Xenopus extract
}

\author{
GARY S. MCDOWELL*,1,2,3 and ANNA PHILPOTTT,5 \\ ${ }^{1}$ Center for Regenerative and Developmental Biology, Department of Biology, Tufts University, Medford, MA, USA, \\ ${ }^{2}$ The Future of Research (www.futureofresearch.org), Abington, MA, ${ }^{3}$ Manylabs (www.manylabs.org), San Francisco, CA, \\ USA, ${ }^{4}$ Department of Oncology, MRC/Hutchison Research Centre, University of Cambridge, Cambridge Biomedical Campus, \\ Cambridge, UK and ${ }^{5}$ Wellcome Trust - Medical Research Council, Cambridge Stem Cell Institute, Cambridge, UK
}

\begin{abstract}
The small protein modifier, ubiquitin, can be covalently attached to proteins in the process of ubiquitylation, resulting in a variety of functional outcomes. In particular, the most commonly-associated and well-studied fate for proteins modified with ubiquitin is their ultimate destruction: degradation by the $26 \mathrm{~S}$ proteasome via the ubiquitin-proteasome system, or digestion in lysosomes by proteolytic enzymes. From the earliest days of ubiquitylation research, a reliable and versatile "cell-in-a-test-tube" system has been employed in the form of cytoplasmic extracts from the eggs and embryos of the frog Xenopus laevis. Biochemical studies of ubiquitin and protein degradation using this system have led to significant advances particularly in the study of ubiquitin-mediated proteolysis, while the versatility of Xenopus as a developmental model has allowed investigation of the in vivo consequences of ubiquitylation. Here we describe the use and history of Xenopus extract in the study of ubiquitin-mediated protein degradation, and highlight the versatility of this system that has been exploited to uncover mechanisms and consequences of ubiquitylation and proteolysis.
\end{abstract}

KEY WORDS: extract system, ubiquitin, degron, protein degradation, 26 S proteasome, Xenopus

\section{Introduction}

Proteins are created through transcription and translation from DNA to RNA, and then finally synthesized at the ribosome (Crick, 1970). In addition to their production, proteins are also destroyed to regulate their levels, terminate their function and recycle their constituent amino acids for future protein syntheses. The study of protein catabolism is a relatively recent area of research. Despite early observations that proteins were broken down and their components reused (Schoenheimer et al., 1939; Schoenheimer, 1942), there was significant resistance to the concept that proteins were not persistent, and degraded intracellularly (Hogness et al., 1955). It was only after extensive investigation (Hershko et al., 1980; Schimke and Doyle, 1970; Simpson, 1953) that protein degradation came to be accepted, and the ubiquitin (Ub) protein was identified as a mediator of ATP-dependent protein degradation (Ciehanover et al., 1978; Wilkinson et al., 1980).

Ub can be covalently attached to other proteins in the posttranslational modification known as ubiquitylation. Ubiquitylation of proteins can result in a variety of signaling roles (Kerscher et al., 2006), but the best studied outcome of ubiquitylation is protein degradation. Ub-mediated proteolysis can be achieved through degradation by the 26S proteasome through the Ub-Proteasome System (UPS) (Glickman and Ciechanover, 2002), or by digestion in organelles called lysosomes using proteolytic enzymes (Schnell and Hicke, 2003).

The study of protein degradation and ubiquitylation continues to be a highly active and continuously-evolving field (as reviewed in (McDowell and Philpott, 2016)), one which has taken advantage of a number of model systems, and for biochemical studies, the frog Xenopus has played an important role. In particular, Xenopus offers the unique advantage of the ability to generate cell-free cytoplasmic extracts, which contain soluble proteins capable of carrying out the biochemical modifications required for protein ubiquitylation and destruction, facilitating many important advances in this field. Here, we describe the Xenopus cell-free cytosolic extract system and illustrate its utility in the study of protein ubiquitylation and degradation.

Abbreviations used in this paper: APC/C, anaphase-promoting complex/cyclosome; bHLH, basic helix-loop-helix; CSF, cytostatic factor; D-box, destruction box; ID, intrinsic disorder; KEN box, Lys-Glu-Asn box; Ngn, neurogenin; PTM, posttranslational modification; Ub, ubiquitin; UPS, ubiquitin-proteasome system.

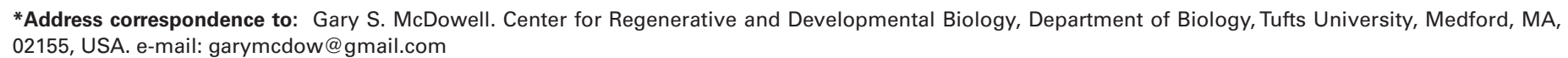

Accepted: 13 June, 2016.

ISSN: Online 1696-3547, Print 0214-6282 


\section{Xenopus extract systems}

Xenopus is an ideal model organism for biochemical studies due to its unique tractable extract system; milliliter volumes of cytosol readily generated from the thousands of eggs a single female frog can lay in one day can be used to study ubiquitylation and protein destruction events in vitro. Cytosolic extracts were first generated using unfertilized eggs from Xenopus laevis to demonstrate the assembly of chromatin from DNA (Laskey et al., 1977), but have been readily adapted for study of a variety of biochemical and cell biological regulatory mechanisms. The extracts that are used most commonly to investigate mechanisms of ubiquitylation are "cell cycle" extracts. These have been further modified over time to suit the requirements of the researcher, and often developed from the protocols laid down by Andrew Murray (Murray, 1991).

Activated interphase cell cycle extracts, made using the general protocol illustrated in Fig. 1, were first developed by Manfred Lohka in the lab of Yoshio Masui using Rana pipiens cytosol to study pronuclear formation with Xenopus laevis sperm nuclei (Lohka and Masui, 1983; Powell, 2005). Modified versions, which still retained activity after extract was frozen and thawed, were used to study DNA replication (Blow and Laskey, 1986) and, as we will



discuss later, to study cyclin degradation. These studies involved both "low-speed" extracts (generated after low speed centrifugation that include light membranes, ribosomes and nuclear envelope (Felix et al., 1989b)) and "high-speed" extracts (generated after an additional second, faster centrifugation to remove membranes and ribosomes (Felix et al., 1989a)). Extracts that could go through multiple cell cycles were also developed (Hutchison et al., 1987; Murray and Kirschner, 1989). In addition, non-activated or cytostatic factor (CSF)-arrested meiotic metaphase extracts have been generated, replicating the environment of the unfertilized egg and these could later be activated with the addition of calcium ((Lohka and Maller, 1985) and refined (Murray et al., 1989)). Protocols for both activated interphase and CSF-arrested mitotic extracts were described in detail by Murray (Murray, 1991). In addition to eggbased extracts, we have also used embryonic extracts, generated by centrifugation of embryos at particular stages of development, to mimic developmental stages such as neurogenesis (McDowell et al., 2010). Protocols for the preparation of a variety of cytosolic extracts to answer many experimental questions can be found at the community portal for the Xenopus community, Xenbase (www. xenbase.org/, (James-Zorn et al., 2015; Karpinka et al., 2015)).

The utility of the Xenopus extract system to study a variety of biological problems is clear (e.g., (Murray, 1991; Nikos, 2012; Zyłkiewicz and Stukenberg, 2014) and many others). Here we are focusing on its use in the study of proteolysis, where the simplicity of the ubiquitylation and degradation assays that the extract system allows has been key to the significant advances that have resulted (see (Klotzbucher et al., 2002; Salic et al., 2000; Vosper et al., 2009) for examples of Ub protocols). In addition, it has been straightforward to determine how biochemical mechanisms relate to the situation in vivo by using the developmentally tractable Xenopus embryo system. Importantly, mechanisms identified in frog have been widely shown to be conserved in mammalian systems, demonstrating the utility of this "cell-in-a-test-tube" analytical approach.

\section{The machinery of ubiquitylation}

The pathway leading to UPS-mediated protein degradation is now well characterized and is discussed in more detail elsewhere ((Hershko and Ciechanover, 1998; McDowell and Philpott, 2013; McDowell and Philpott, 2016; Varshavsky, 1997). In brief, Ub is activated by an E1 enzyme (Hershko et al., 1981), passed to an Ub-conjugating (E2) enzyme (Hershko et al., 1983) and from there to a substrate protein, specified by the particular E3 ligase that binds both the substrate and the E2 (Hershko et al., 1986). Multiple rounds of ubiquitylation on $\mathrm{Ub}$ itself can then follow to

Fig. 1. Xenopus laevis egg extract systems in ubiquitylation studies. (A) Xenopus laevis are induced with hormone to lay eggs; (B) eggs are collected and their jelly coats removed; (C) eggs are activated using calcium ionophore to mimic fertilization and direct entry into interphase. Activated eggs are then spun at high speeds in a centrifuge to separate into (D) (i) lipid, (ii) cytoplasmic, and (iii) pigment granule and yolk platelet layers. (E) The cytoplasmic layer is taken and used for in vitro studies: for example, (F) in vitro translated radiolabelled protein is added to extract supplemented with Ub and ATP, and aliquots removed at various time points to assay degradation of protein over time; and $(\mathbf{G})$ in vitro translated radiolabelled protein is added to extract supplemented with tagged $\mathrm{Ub}$ and the proteasome inhibitor MG132, and after an incubation period antibody-coated beads are added to isolate ubiquitylated proteins under various conditions. 
create chains of polyUb. The polyUb modification most commonly understood to target proteins for UPS-mediated degradation is a tetramer of K48-linked Ub moieties (Thrower et al., 2000). However many novel chains, of homotypic, heterotypic, and even branched topologies are contributing to the study of "atypical" chain ubiquitylation (Komander, 2009). It was observed that purification of the Anaphase-Promoting Complex/Cyclosome (APC/C), a cell-cycle dependent component of the ubiquitylation machinery, from Xenopus extract at different salt conditions led to the formation of Ub chains of differing lengths and in particular showed the capacity, at least in vitro, for the APC/C to form K11-, K48- and K63-linked polyUb chains targeting protein substrates for degradation (Kirkpatrick et al., 2006). Upon further refinement, this led to work on the precise mechanism for the formation of K11-linked chains by the APC/C using the specificity conferred by the E2, UBE2S (Wu et al., 2010). The Xenopus system has played a central role in identifying which proteins are targeted for degradation and when.

\section{Discoveries of Degrons and cell cycle regulated proteolysis}

The use of Xenopus extracts has been central to our understanding of mechanisms that regulate the destruction of proteins to bring about cell cycle transitions, as they can readily be manipulated to mimic the cellular conditions of interphase and mitosis and it has been known for a long time that cell cycle progression is accompanied by the cyclical synthesis and destruction of a number of proteins (Koepp, 2014).

Global Ub metabolism is not obviously regulated by the cell cycle; using cycling Xenopus egg extract, it was possible to show that the levels of $\mathrm{Ub}$ did not change with the cell cycle phase; the rates of conjugation, protein degradation, and isopeptidase activity all remained constant throughout the course of the cycling extract experiments (Mahaffey et al., 1993). However, some proteins such as cyclins are destroyed at specific points in the cell cycle (Glotzer et al., 1991). The authors concluded that, therefore, cell cycle differences in cyclin degradation could not be accounted for by any obvious global differential Ub kinetics in different phases of the cell cycle, but instead must result from individual regulation of specific proteins. In fact, the experiments by Glotzer et al., suggested that the recognition of cyclin $B$ by the ubiquitylation machinery itself promotes the entry of the cell cycle into anaphase ((Glotzer et al., $1991)$; prior to this work, only one other case of physiological regulation through Ub-mediated degradation had been identified, the plant protein phytochrome (Jabben et al., 1989)). In this landmark study, Glotzer and colleagues found that the $\mathrm{N}$-terminal region of cyclin $\mathrm{B}$ was required for its degradation in a mitotic extract system and that cyclin B was itself ubiquitylated (Glotzer et al., 1991). In the absence of inhibitors of ubiquitylation or proteasomal inhibitors that had yet been described, the authors instead were able to demonstrate the link between ubiquitylation and degradation of cyclin $\mathrm{B}$ by calculating the kinetics of protein degradation compared with the flow of cyclin B through ubiquitylated intermediates (Glotzer et al., 1991).

As well as demonstrating the role of cyclin B destruction in the cell cycle, these and further Xenopus extract experiments have shown us that cell cycle regulated destruction of proteins such as cyclins relies on timed degradation orchestrated by sequences known as degrons (Glotzer et al., 1991; King et al., 1996; Pfleger and Kirschner, 2000; Reed, 2003; van der Velden and Lohka, 1993). Degrons are the minimal signals within proteins that result in their targeting for degradation by proteolytic machinery (Ravid and Hochstrasser, 2008). Here we will discuss two well-known degrons identified using Xenopus extract systems that are targeted by the E3 ubiquitin ligase Anaphase Promoting Complex/ Cyclosome (APC/C see below): the KEN (Lys-Glu-Asn) box and Destruction (D-box, Arg-X-X-Leu).

The $D$-box was first identified during the early investigations of the degradation of the cell cycle regulator cyclin B, showing that a particular region of the $\mathrm{N}$-terminus of the cyclin was necessary and sufficient to target for degradation in Xenopus mitotic extract; stable entry of extract into mitosis could be brought about by addition of a form of cyclin B with the first 90 amino acid residues deleted (a technique still used to generate mitotic egg extract), while adding this $\mathrm{N}$-terminal portion of cyclin to other proteins was enough to trigger their proteolytic degradation (Glotzer et al., 1991). The characterization of the precise degron, the $D$ box, within the Cyclin B N-terminal region was further refined using a mutagenesis approach, followed by investigation of the kinetics of protein degradation in Xenopus extract systems (King et al., 1996). Furthermore, important differences between control of cyclins Aand $B$ destruction were also identified, resulting from differing residues within their respective degrons (King et al., 1996).

The discovery of the KEN box, a distinct degron targeting proteins for cell cycle regulated destruction, using Xenopus extract highlighted an important mechanism for cell-cycle regulation of protein degradation by the APC/C multi-component E3 ligase (see below). The association of $\mathrm{Cdc} 20$ with core components results in the mitotically active form of the APC/C, while the association of Cdh1 generates the interphase form (Fang et al., 1998; Schwab et al., 1997; Visintin et al., 1997). While Cdc20 mitotic substrates contain the D-box (Glotzer et al., 1991), Cdh1 could target both Dbox and non-D-box-containing proteins for degradation. As Cdc20 itself lacks a D-box but is degraded in a Cdh1-dependent manner, it was ideal to use for identification of other potential degrons, and this resulted in the discovery of the KEN box (Pfleger and Kirschner, 2000). Additional substrates such as proteins Nek2 and B99 were also found to be ubiquitylated and degraded by the natural presence of KEN boxes and, like the D-box (Glotzer et al., 1991; King et al., 1996), the KEN box can target heterologous proteins for degradation when fused to them (Pfleger and Kirschner, 2000).

The anaphase-promoting complex (or APC) was discovered using Xenopus extract systems (King et al., 1995) at a similar time to the discovery of the cyclosome in clam oocyte extracts (Sudakin et al., 1995). Now collectively known as the APC/C, the identification of this multi-protein ubiquitylation complex that shows cell cycle stage-specific activation by Cdc20 and Cdh1 (see above), and the identification of cell cycle regulated degrons, combine to explain the cell cycle regulation of cyclin stability. It is not possible to overemphasize the role of Xenopus extract in facilitating the discovery of the APC/C and for further elucidating its function; for instance the identification of key binding regulatory proteins such as Cdc20 was made possible using exploratory experiments in Xenopus extract along with work in HeLa cell extracts (Fang et al., 1998). Similarly, the identification of Mad2L2 as a regulator of Cdh1 dissociation, and the proposal of a mechanism for Mad2-mediated Cdc20 dissociation and Mad2L2-mediated Cdh1 dissociation from the APC/C, were made possible through Xeno- 
pus extract-based assays of APC/C activity (Pfleger et al., 2001). Identification of subunits such as BIME (Peters et al., 1996) and additional components such as Fizzy required in APC/C activation (Lorca et al., 1998) were also all absolutely dependent on using Xenopus extract systems. It was also possible to characterize the kinetics of cyclin ubiquitylation to reveal more general properties of cyclin B protein proteasomal degradation, as described above (Glotzer et al., 1991). For instance, using Xenopus extract, Yu et al., purified the E2 enzyme UBCx from interphase egg extracts (Yu et al., 1996), and were thus able to identify and characterize a previously observed Ub-conjugating activity targeting cyclin B (King et al., 1995). A crucial substrate of the APC/C, securin, the degradation of which is required for the separation of sister chromatids during mitosis across vertebrate species (Zou et al., 1999) was first identified and its degradation characterized in Xenopus extract (Holloway et al., 1993). Ubiquitylation, and in particular cell cycle-regulated ubiquitylation, is often further regulated by additional post-translational modifications such as phosphorylation (Harper, 2002; Hunter, 2007; Pagano, 1997). For instance, ubiquitylation and degradation of c-Mos after fertilization of Xenopus eggs is regulated by its phospho-status; addition of anti-Fizzy antibodies maintains high cyclin $\mathrm{B} / \mathrm{cdc} 2$ and this prevents $\mathrm{c}$-Mos dephosphorylation and its subsequent degradation, while anti-Fizzy antibodies had no effect on c-Mos dephosphorylation and destruction 15 minutes after activation, when cyclin B was already degraded (Castro et al., 2001). Cyclin degradation is itself regulated by c-Mos, through the activation of MAP kinase which can prevents cyclin B-cdc2 kinase-triggered cyclin destruction (Abrieu et al., 1996). By adding c-Mos protein to CSF-arrested egg extracts, the authors found that the cyclin degradation machinery was poised, but not inactivated, as release of the extract from the CSF block by addition of Ca2+-calmodulin-dependent protein kinase II allowed the degradation machinery to function normally (Abrieu et al., 1996). Most recently, Xenopus extract has been used to demonstrate that Cdk1 activates the APC/C through regulation of phosphorylation events (Fujimitsu et al., 2016).

Taken together, it is clear that work by the Kirschner (Fang et al., 1998; Glotzer et al., 1991; King et al., 1995; King et al., 1996; Murray et al., 1989; Peters et al., 1996; Pfleger et al., 2001; Pfleger and Kirschner, 2000; Yu etal., 1996), Hunt (Felix etal., 1989b; Felix et al., 1989a; Stewart et al., 1994), and Lohka (van der Velden and Lohka, 1993) labs in particular, alongside important contributions from a number of other researchers using the Xenopus extract system, has been formative in instructing our current understanding of cyclin destruction and cell cycle regulation of protein degradation.

\section{Ubiquitylation and DNA Replication}

Protein degradation also plays a key role in regulation of DNA replication, and this has also been extensively characterized using Xenopus extracts. For instance, Geminin, an important negative regulator of DNA replication (McGarry and Kirschner, 1998) which also has a distinct role in neural induction (Kroll et al., 1998) was first identified by an unbiased screen set up to identify proteins destroyed specifically in mitosis (McGarry and Kirschner, 1998) and shown to regulate stability of the replication factor Cdt1 in Xenopus extract (Arias and Walter, 2005). Ub-mediated regulation of other DNA replication factors has also been studied by additional methods in Xenopus extracts. For instance, in the initiation of DNA replication, the requirement for Cdc34 as a Ubconjugating enzyme to target proteins for degradation and drive entry into S-phase was established using methyl-Ub-supplemented Xenopus extracts (Yew and Kirschner, 1997). DNA replication was inhibited by generally blocking Ub-mediated proteasomal degradation. It was also postulated that Cdc34 may regulate the cdk inhibitor Xic1's degradation and indeed in extracts with sperm nuclei added, Xic1 was efficiently degraded. It is possible to use antibodies to immunodeplete factors from egg extracts and then assay the effect on biochemical processes, and indeed, Xic1 was stable in Cdc34-depleted extracts (Yew and Kirschner, 1997). This observation suggested a close link between Xic1 degradation and replication, in particular for formation of a prereplication complex requiring $\mathrm{Cdk} 2, \mathrm{Cdc} 7$ and $\mathrm{Cdc} 45$ before Xic1 could be degraded; upon completion of DNA replication Xic1 is stabilized (You et al., 2002). Findings that the Xic1 degradation rate correlated with the concentration of sperm nuclei in extract (Yew and Kirschner, 1997) were explained by the finding that chromatin and a nuclear environment were required for Xic1 degradation to occur (You et al., 2002). Moreover, depletion of the chromatin-bound licensing factor Mcm 7 from extracts inhibited both Xic1 degradation and DNA replication by preventing the formation of prereplication complexes on chromatin (You et al., 2002). Therefore a variety of Xenopus extract depletion studies and degradation assays, previously used to demonstrate the cell cycle dependence of Ub-mediated protein degradation, have also been modified to highlight the relationship between ubiquitylation and DNA replication.

\section{Ub-mediated degradation of Neurogenin2; complex regulation in eggs and embryos}

Ubiquitylation usually occurs on one or more lysine residues. However, other residues are nevertheless capable of forming bonds with Ub molecules and these can also target proteins for destruction. Non-canonical ubiquitylation describes the modification of protein substrates with Ub on residues other than the canonical Iysine residue (Freiman and Tjian, 2003) and in particular on the $\mathrm{N}$-terminal amino group; the thiol group of cysteine residues; and the hydroxyl group of serine and threonine residues, all of which have the potential [and as shown in Tables 1, 2 and 3 of (McDowell and Philpott, 2016), the demonstrated activity] to react with and covalently link to Ub. Our own laboratory has investigated these non-canonical ubiquitylation events by looking in detail at the degradation of the proneural basic helix-loop-helix (bHLH) transcription factor Neurogenin2 (Ngn2, see Fig. 2). This has proved to be surprisingly complex.

The original observations, in Xenopus laevis interphase egg extract, showed that Ngn2 where all lysines had been mutated to alanines could nevertheless be ubiquitylated and degraded efficiently. Ub moieties could be directly added onto the $\mathrm{N}$-terminus of Ngn2. Moreover, an N-terminally blocked lysine-less mutant of Ngn2 could be further ubiquitylated by bonds that were sensitive to reducing agents and showing $\mathrm{pH}$-dependency, implicating Ub linkages to cysteines, serines and threonines ((Vosper et al., 2009), as reviewed in (Kravtsova-Ivantsiv et al., 2015; McDowell and Philpott, 2013; McDowell and Philpott, 2016)). Non-canonical ubiquitylation was of differing importance for Ngn2 protein stability in interphase versus mitosis; we saw that mutation of all the cysteines in Ngn2 had no effect on stability in interphase, but was 
stabilizing in mitotic extracts (Vosper et al., 2009). Good evidence for non-canonical ubiquitylation of $\mathrm{Ngn} 2$ driving its destruction was also found in extracts from neurula-stage Xenopus embryos, indicating that this was not an egg-specific phenomenon. Indeed, similar non-canonical regulation was observed in mouse embryonal carcinoma cells, demonstrating that even unusual regulatory mechanisms first uncovered in Xenopus extracts are nevertheless active in vivo in frogs and in mammalian cells (McDowell et al., 2010). It is important to note, however, that we have since showed that the closely related proteins $\mathrm{Ngn} 2$ and $\mathrm{Ngn} 3$ show somewhat different control of ubiquitylation and destruction, and this demonstrates the possible need to consider these regulatory mechanisms on a protein by protein basis (Roark et al., 2012).

We have also undertaken a detailed investigation of the effects of cell cycle-regulated phosphorylation on Ngn2 protein activity (Ali et al., 2011; Hindley et al., 2012; McDowell, Hindley, et al., 2014) and it is now clear that the relationship between Ngn2 phosphorylation and protein stability is complex. The half-life of Ngn2 protein can be readily calculated by addition of radiolabelled in vitro translated
Ngn2 protein to Xenopus extracts, removing samples at increasing times, and quantitating the amount of protein left after SDS PAGE and autoradiography ((Vosper et al., 2007), Fig. 1). Ngn2 is phosphorylated on multiple serine-proline motifs (Ali et al., 2011). Mutation of these serines to alanines does not alter the half life of Ngn2 in interphase or mitotic extracts. However, Ngn2 protein is stabilized by addition of its heterodimeric $\mathrm{E}$ protein binding partner and this is regulated by the availability of these serines; the phosphomutant protein is more readily stabilized than the wildtype protein (Ali et al., 2011; McDowell, Hindley, et al., 2014). This is in contrast to experiments looking at another potential casein kinase II phosphomutant of Ngn2, T118A, which was not as well protected from degradation as the wild type protein (Vosper et al., 2007). Moreover, fusion of Ub directly to the N-terminus of Ngn2 reduced its half-life dramatically, as well as significantly inhibiting its ability to drive neuronal differentiation, though the effect on neuronal differentiation of this fusion was less pronounced for the phosphomutant version of the protein (Hindley et al., 2012). These experiments, which use egg and embryo extracts in parallel with in vivo analyses, demonstrate clearly the versatility of Xenopus as a model system to study the functional consequences of ubiquitylation.

In addition to ubiquitylation (or sometimes even without ubiquitylation (Prakash et al., 2009)), unfolding initiation sites are required to allow protein degradation by the UPS (Prakash etal., 2004) and in particular proteins that are natively unfolded, lacking regular structure (intrinsically disordered or ID proteins (Dunker et al., 2001)) may be particularly susceptible to Ub-mediated degradation (Gsponer etal., 2008; McDowell and Philpott, 2016). We investigated the role of ID in the degradation of Ngn2 using Xenopus extract systems (McDowell, Hardwick, et al., 2014), comparing Ngn2 and the related bHLH transcription factor NeuroD1, which is similarly structured but has very different degradation properties (Vosper et al., 2007). Both are ubiquitylated, but only Ngn2 is ubiquitylated on non-canonical sites (McDowell, Hardwick, et al., 2014), and it is degraded considerably faster than NeuroD. Using the extract system to compare the stability of a variety of chimeric proteins where we swapped $\mathrm{N}$-, $\mathrm{C}$ - and bHLH domains between Ngn2 and NeuroD1, we found that despite the disorder in the $\mathrm{N}$ - and $\mathrm{C}$-terminal domains likely in both proteins, the bHLH domain itself (which is still highly disordered (AguadoLlera et al., 2010) but has a much more highly conserved sequence between the two proteins (Bertrand et al., 2002)) was the region that appeared to most greatly influence chimeric protein activity and stability (McDowell, Hardwick, et al., 2014). This analysis was only possible because of

Fig. 2. Regulation of neurogenin2 (Ngn2). Schematic illustrating points of regulation of Ngn2 by ubiquitylation, phosphorylation and structurally, with and without its heterodimeric E12 binding partner. 
our ability to carry out a very large number of degradation assays using the Xenopus extract system. The other great advantage of Xenopus was also to have the in vivo system working in parallel to assess functional activity of the chimeric proteins, allowing us to determine the relationship between structure, activity and stability. This relationship has proved to be remarkably complex ((Ali et al., 2011; Hindley et al., 2012; McDowell, Hardwick, et al., 2014; McDowell, Hindley, et al., 2014), see Fig. 2).

\section{Ubiquitylation in a developmental context}

Most of the insights into ubiquitylation gained using Xenopushave come from biochemical analyses in extract systems as described above, and in general, most attention has been paid to degradation mechanisms found in the egg. However, many proteins are degraded at specific times in development, and there has been some work in both egg and embryo extracts that has addressed control of ubiquitylation and destruction of proteins only found expressed at later developmental stages (including Ngn2 as described above). Indeed, the great benefit of studying Ub-mediated protein degradation in Xenopus is the ability to put the biochemical information into a developmental context. For instance, Xic1 is targeted for degradation by the F-box protein Skp2, and its degradation has been studied in egg extracts as well as in embryos (Boix-Perales et al., 2007; Lin et al., 2006). The degradation of Skp2 itself by the APC/C has been studied in Xenopus extract by ubiquitylation and degradation assays (Wei et al., 2004) and its function analyzed in developing embryos (Boix-Perales et al., 2007).

One of the most interesting studies of Ub-mediated protein degradation in a developmental context is the study of $\beta$-catenin regulation in extracts from eggs and embryos, with implications for the study of Wnt signaling in embryogenesis (Salic et al., 2000). Again, the strength of this approach lies in the ability to compare the effects of various treatments on beta-catenin stability, as well as other components of the Wnt signaling pathway, with developmental defects that are observed, such as problems with axis formation [see Table 1 in Salic et al., (2000)].

\section{Concluding remarks}

Since the relatively recent discovery of $\mathrm{Ub}$ and acceptance of intracellular protein catabolism, degradation of proteins by the $26 \mathrm{~S}$ proteasome via the Ub-proteasome system has become an area of intense study across biochemical, cell biology, developmental and clinical disciplines. From the earliest days of ubiquitylation research the "cell-in-a-test-tube" system of the frog Xenopus laevis has catalyzed the discovery of components of this machinery. Combined with the versatility of Xenopus as a developmental model, this has allowed investigation of the in vivo consequences of ubiquitylation as well as in vitro assays more geared to biochemical analysis. Overall, the availability of large quantities of extract from the eggs of a single frog in which ubiquitylation and protein degradation can occur, the speed with which experiments can be carried out, and the ability to compare in vitro finding with effects in vivo in a rapid and well-characterized developmental context, have made Xenopus a crucial model organism for studying ubiquitylation and protein degradation. Its high level of versatility means it will remain a highly valued system for continued studies of Ub-mediated degradation.

\section{Acknowledgements}

Research in AP's laboratory is supported by Medical Research Council grants MR/K018329/1 and MR/L021129/1, and core support from the Wellcome Trust and MRC to the Wellcome Trust-Medical Research Council Cambridge Stem Cell Institute. GM was supported by Michael Levin at Tufts University through grants from the G. Harold and Leila Y. Mathers Charitable Foundation and the Physical Science Oncology Center supported by Award Number U54CA143876 from the National Cancer Institute.

\section{References}

ABRIEU A, LORCA T, LABBÉ JC, MORIN N, KEYSE S, DORÉE M (1996). MAP kinase does not inactivate, but rather prevents the cyclin degradation pathway from being turned on in Xenopus egg extracts. J Cell Sci 109 (Pt 1): 239-246.

AGUADO-LLERA D, GOORMAGHTIGH E, DE GEEST N, QUAN XJ, PRIETO A HASSAN BA, GÓMEZ J, NEIRA JL (2010). The basic helix-loop-helix region of human neurogenin 1 is a monomeric natively unfolded protein which forms a "fuzzy" complex upon DNA binding. Biochemistry 49: 1577-1589.

ALI F, HINDLEY C, MCDOWELL G, DEIBLER R, JONES A, KIRSCHNER M, GUILLEMOT F, PHILPOTT A (2011). Cell cycle-regulated multi-site phosphorylation of Neurogenin 2 coordinates cell cycling with differentiation during neurogenesis. Development 138: 4267-4277.

ARIAS EE, WALTER JC (2005). Replication-dependent destruction of Cdt1 limits DNA replication to a single round per cell cycle in Xenopus egg extracts. Genes Dev 19: 114-126.

BERTRAND N, CASTRO DS, GUILLEMOT F (2002). Proneural genes and the specification of neural cell types. Nat Rev Neurosci 3: 517-530.

BLOW JJ, LASKEY RA (1986). Initiation of DNA replication in nuclei and purified DNA by a cell-free extract of Xenopus eggs. Cell 47: 577-587.

BOIX-PERALES H, HORAN I, WISE H, LIN HR, CHUANG LC, YEW PR, PHILPOTT $A(2007)$. The E3 ubiquitin ligase skp2 regulates neural differentiation independent from the cell cycle. Neural Dev 2: 27.

CASTRO A, PETER M, MAGNAGHI-JAULIN L, VIGNERON S, GALAS S, LORCAT, LABBÉ JC (2001). Cyclin B/cdc2 induces c-Mos stability by direct phosphorylation in Xenopus oocytes. Mol Biol Cell 12: 2660-2671.

CIEHANOVERA, HOD Y, HERSHKO A (1978). A heat-stable polypeptide component of an ATP-dependent proteolytic system from reticulocytes. Biochem Biophys Res Commun 81: 1100-1105.

CRICK F (1970). Central dogma of molecular biology. Nature 227: 561-563.

DUNKER A, LAWSON J, BROWN C, WILLIAMS R, ROMERO P, OH J, OLDFIELD C CAMPEN A, RATLIFF C, HIPPS K, et al., (2001). Intrinsically disordered protein. J. Molec. Graph. Modelling 19: 26-59.

FANG G, YU H, KIRSCHNER MW (1998). Direct binding of CDC20 protein family members activates the anaphase-promoting complex in mitosis and $\mathrm{G} 1$. Mol Cell 2: 163-171.

FELIX MA, PINES J, HUNT T, KARSENTI E (1989a). A post-ribosomal supernatant from activated Xenopus eggs that displays post-translationally regulated oscillation of its cdc2+ mitotic kinase activity. EMBO J 8: 3059-3069.

FELIX MA, PINES J, HUNT T, KARSENTI E (1989b). Temporal regulation of cdc2 mitotic kinase activity and cyclin degradation in cell-free extracts of Xenopus eggs. J Cell Sci Suppl 12: 99-116.

FREIMAN RN, TJIAN R (2003). Regulating the regulators: lysine modifications make their mark. Cell 112: 11-17.

FUJIMITSU K, GRIMALDI M, YAMANO H (2016). Cyclin dependent kinase 1-dependent activation of APC/C ubiquitin ligase. Science 352: 1121-1124.

GLICKMAN MH, CIECHANOVER A (2002). The ubiquitin-proteasome proteolytic pathway: destruction for the sake of construction. Physiol Rev 82: 373-428.

GLOTZER M, MURRAY AW, KIRSCHNER MW (1991). Cyclin is degraded by the ubiquitin pathway. Nature 349: 132-138.

GSPONER J, FUTSCHIK ME, TEICHMANN SA, BABU MM (2008). Tight regulation of unstructured proteins: from transcript synthesis to protein degradation. Science 322: 1365-1368.

HARPER JW (2002). A phosphorylation-driven ubiquitination switch for cell-cycle control. Trends Cell Biol 12: 104-107. 
HERSHKO A, CIECHANOVER A (1998). The ubiquitin system. Annu Rev Biochem 67: 425-479.

HERSHKO A, CIECHANOVER A, HELLER H, HAAS AL, ROSE IA (1980). Proposed role of ATP in protein breakdown: conjugation of protein with multiple chains of the polypeptide of ATP-dependent proteolysis. Proc NatIAcad SciUSA77:1783-1786.

HERSHKO A, CIECHANOVER A, ROSE IA (1981). Identification of the active amino acid residue of the polypeptide of ATP-dependent protein breakdown. $J$ Biol Chem 256: 1525-1528.

HERSHKO A, HELLER H, ELIAS S, CIECHANOVER A (1983). Components of ubiquitin-protein ligase system. Resolution, affinity purification, and role in protein breakdown. J Biol Chem 258: 8206-8214.

HERSHKO A, HELLER H, EYTAN E, REISS Y (1986). The protein substrate binding site of the ubiquitin-protein ligase system. J Biol Chem 261: 11992-11999.

HINDLEY C, ALI F, MCDOWELL G, CHENG K, JONESA, GUILLEMOT F, PHILPOTT $A$ (2012). Post-translational modification of Ngn2 differentially affects transcription of distinct targets to regulate the balance between progenitor maintenance and differentiation. Development 139: 1718-1723.

HOGNESS DS, COHN M, MONOD J (1955). Studies on the induced synthesis of beta-galactosidase in Escherichia coli: the kinetics and mechanism of sulfur incorporation. Biochim Biophys Acta 16: 99-116.

HOLLOWAY SL, GLOTZER M, KING RW, MURRAY AW (1993). Anaphase is initiated by proteolysis rather than by the inactivation of maturation-promoting factor. Cell 73: 1393-1402.

HUNTERT (2007). The age of crosstalk: phosphorylation, ubiquitination, and beyond. Mol Cell 28: 730-738.

HUTCHISON CJ, COX R, DREPAUL RS, GOMPERTS M, FORD CC (1987). Periodic DNA synthesis in cell-free extracts of Xenopus eggs. EMBO J 6: 2003-2010.

JABBEN M, SHANKLIN J, VIERSTRA RD (1989). Ubiquitin-phytochrome conjugates. Pool dynamics during in vivo phytochrome degradation. J Biol Chem 264: 4998-5005.

JAMES-ZORN C, PONFERRADA VG, BURNS KA, FORTRIEDE JD, LOTAY VS, LIU Y, BRAD KARPINKA J, KARIMI K, ZORN AM, VIZE PD (2015). Xenbase: Core features, data acquisition, and data processing. Genesis 53: 486-97.

KARPINKA JB, FORTRIEDE JD, BURNS KA, JAMES-ZORN C, PONFERRADA VG, LEE J, KARIMI K, ZORN AM, VIZE PD (2015). Xenbase, the Xenopus model organism database; new virtualized system, data types and genomes. Nucleic Acids Res 43: D756-D763.

KERSCHER O, FELBERBAUM R, HOCHSTRASSER M (2006). Modification of proteins by ubiquitin and ubiquitin-like proteins. Annu Rev Cell Dev Biol22: 159-180.

KING RW, GLOTZER M, KIRSCHNER MW (1996). Mutagenic analysis of the destruction signal of mitotic cyclins and structural characterization of ubiquitinated intermediates. Mol Biol Cell 7: 1343-1357.

KING RW, PETERS JM, TUGENDREICH S, ROLFE M, HIETER P, KIRSCHNER MW (1995). A 20S complex containing CDC27 and CDC16 catalyzes the mitosisspecific conjugation of ubiquitin to cyclin B. Cell 81: 279-288.

KIRKPATRICK DS, HATHAWAY NA, HANNA J, ELSASSER S, RUSH J, FINLEY D, KING RW, GYGI SP (2006). Quantitative analysis of in vitro ubiquitinated cyclin B1 reveals complex chain topology. Nat Cell Biol 8: 700-710.

KLOTZBUCHER A, PASCREAU G, PRIGENT C, ARLOT-BONNEMAINS Y (2002). A Method for Analyzing the Ubiquitination and Degradation of Aurora-A. Biol Proced Online 4: 62-69.

KOEPP DM (2014). Cell cycle regulation by protein degradation. Methods Mol Biol 1170: 61-73.

KOMANDER D (2009). The emerging complexity of protein ubiquitination. Biochem Soc Trans 37: 937-953.

KRAVTSOVA-IVANTSIV Y, SHOMER I, COHEN-KAPLAN V, SNIJDER B, SUPERTIFURGA G, GONEN H, SOMMER T, ZIV T, ADMON A, NARODITSKY I, JBARA M, BRIK A, PIKARSKY E, KWON YT, DOWECK I, CIECHANOVER A (2015). KPC1-Mediated Ubiquitination and Proteasomal Processing of NF-KB1 p105 to p50 Restricts Tumor Growth. Cell 161: 333-347.

KROLL KL, SALIC AN, EVANS LM, KIRSCHNER MW (1998). Geminin, a neuralizing molecule that demarcates the future neural plate at the onset of gastrulation. Development 125: 3247-3258.

LASKEY RA, MILLS AD, MORRIS NR (1977). Assembly of SV40 chromatin in a cell-free system from Xenopus eggs. Cell 10: 237-243.
LIN H, CHUANG L, BOIX-PERALES H, PHILPOTTA, YEW PR (2006). Ubiquitination of Cyclin-Dependent Kinase Inhibitor, Xic1, is Mediated by theXenopus F-box Protein xSkp2. Cell Cycle 5: 304-314.

LOHKAMJ, MALLERJL(1985). Induction of nuclear envelope breakdown, chromosome condensation, and spindle formation in cell-free extracts. J Cell Biol 101:518-523.

LOHKA MJ, MASUI Y (1983). Formation in vitro of sperm pronuclei and mitotic chromosomes induced by amphibian ooplasmic components. Science 220: 719-721.

LORCA T, CASTRO A, MARTINEZ AM, VIGNERON S, MORIN N, SIGRIST S, LEHNER C, DORÉE M, LABBÉ JC (1998). Fizzy is required for activation of the $\mathrm{APC} /$ cyclosome in Xenopus egg extracts. EMBO J 17: 3565-3575.

MAHAFFEY D, YOO Y, RECHSTEINER M (1993). Ubiquitin metabolism in cycling Xenopus egg extracts. J Biol Chem 268: 21205-21211.

MCDOWELL GS, HARDWICK LJ, PHILPOTTA(2014). Complex domain interactions regulate stability and activity of closely related proneural transcription factors. Biochem Biophys Res Commun 450: 1283-1290.

MCDOWELL GS, HINDLEY CJ, LIPPENS G, LANDRIEU I, PHILPOTT A (2014). Phosphorylation in intrinsically disordered regions regulates the activity of Neurogenin2. BMC Biochem 15: 24.

MCDOWELL GS, KUCEROVA R, PHILPOTT A (2010). Non-canonical ubiquitylation of the proneural protein Ngn2 occurs in both Xenopus embryos and mammalian cells. Biochem Biophys Res Commun 400: 655-660.

MCDOWELL GS, PHILPOTT A (2016). New Insights Into the Role of Ubiquitylation of Proteins. Int. Review Cell Mol Biol. 325: 35-88.

MCDOWELL GS, PHILPOTT A (2013). Non-canonical ubiquitylation: Mechanisms and consequences. Int J Biochem Cell Biol 45: 1833-1842.

MCGARRY TJ, KIRSCHNER MW (1998). Geminin, an inhibitor of DNA replication, is degraded during mitosis. Cell 93: 1043-1053.

MURRAY AW (1991). Chapter 30 Cell Cycle Extracts. In Xenopus laevis: Practical Uses in Cell and Molecular Biology Elsevier, pp. 581-605.

MURRAY AW, KIRSCHNER MW (1989). Cyclin synthesis drives the early embryonic cell cycle. Nature 339: 275-280.

MURRAY AW, SOLOMON MJ, KIRSCHNER MW (1989). The role of cyclin synthesis and degradation in the control of maturation promoting factor activity. Nature 339: 280-286.

NIKOS P (2012). Xenopus laevis as a Model System. Mater. Methods 2: 151.

PAGANO M (1997). Cell cycle regulation by the ubiquitin pathway. FASEB $J 11$ : 1067-1075.

PETERS JM, KING RW, HÖÖG C, KIRSCHNER MW (1996). Identification of BIME as a subunit of the anaphase-promoting complex. Science 274: 1199-1201.

PFLEGER CM, KIRSCHNER MW (2000). The KEN box: an APC recognition signal distinct from the D box targeted by Cdh1. Genes Dev 14: 655-665.

PFLEGER CM, SALIC A, LEE E, KIRSCHNER MW (2001). Inhibition of Cdh1-APC by the MAD2-related protein MAD2L2: a novel mechanism for regulating Cdh1. Genes Dev 15: 1759-1764.

POWELL K (2005). Frog egg extracts can do a cell's work. J Cell Biol 171: 585-585.

PRAKASH S, INOBE T, HATCH AJ, MATOUSCHEKA (2009). Substrate selection by the proteasome during degradation of protein complexes. Nat Chem Biol5:29-36.

PRAKASH S, TIAN L, RATLIFF KS, LEHOTZKY RE, MATOUSCHEK A (2004). An unstructured initiation site is required for efficient proteasome-mediated degradation. Nat Struct Mol Biol 11: 830-837.

RAVIDT, HOCHSTRASSERM (2008). Diversity of degradation signals in the ubiquitinproteasome system. Nat Rev Mol Cell Biol 9: 679-690.

REED SI (2003). Ratchets and clocks: the cell cycle, ubiquitylation and protein turnover. Nat Rev Mol Cell Biol 4: 855-864.

ROARK R, ITZHAKI L, PHILPOTTA(2012). Complex regulation controls Neurogenin3 proteolysis. Biology Open 1: 1264-1272.

SALIC A, LEE E, MAYER L, KIRSCHNER MW (2000). Control of $\beta$-Catenin Stability. Molecular cell 5: 523-532.

SCHIMKE RT, DOYLE D (1970). Control of enzyme levels in animal tissues. Annu Rev Biochem 39: 929-976.

SCHNELL JD, HICKE L (2003). Non-traditional functions of ubiquitin and ubiquitinbinding proteins. J Biol Chem 278: 35857-35860.

SCHOENHEIMERR (1942). The Dynamic State ofBody Constituents, reprint. Harvard 
University Press, Harvard University Press.

SCHOENHEIMERR, RATNERS, RITTENBERG D (1939). The process of continuous deamination and reamination of amino acids in the proteins of normal animals. Science 89: 272-273.

SCHWAB M, LUTUM AS, SEUFERT W (1997). Yeast Hct1 is a regulator of Clb2 cyclin proteolysis. Cell 90: 683-693.

SIMPSON MV (1953). The release of labeled amino acids from the proteins of rat liver slices. J Biol Chem 201: 143-154.

STEWARTE, KOBAYASHI H, HARRISON D, HUNTT (1994). Destruction of Xenopus cyclins $\mathrm{A}$ and $\mathrm{B} 2$, but not $\mathrm{B} 1$, requires binding to p34cdc2. EMBO J 13: 584-594.

SUDAKIN V, GANOTH D, DAHAN A, HELLER H, HERSHKO J, LUCA FC, RUDERMAN JV, HERSHKO A (1995). The cyclosome, a large complex containing cyclin-selective ubiquitin ligase activity, targets cyclins for destruction at the end of mitosis. Mol Biol Cell 6: 185-197.

THROWER JS, HOFFMAN L, RECHSTEINER M, PICKART CM (2000). Recognition of the polyubiquitin proteolytic signal. EMBO J 19: 94-102.

VARSHAVSKY A (1997). The ubiquitin system. Trends Biochem Sci 22: 383-387.

VAN DER VELDEN HM, LOHKA MJ (1993). Mitotic arrest caused by the amino terminus of Xenopus cyclin B2. Mol Cell Biol 13: 1480-1488.

VISINTIN R, PRINZ S, AMON A (1997). CDC20 and CDH1: a family of substratespecific activators of APC-dependent proteolysis. Science 278: 460-463.

VOSPER JM, FIORE-HERICHE CS, HORAN I, WILSON K, WISE H, PHILPOTT A (2007). Regulation of neurogenin stability by ubiquitin-mediated proteolysis. Biochem J 407: 277-284.
VOSPER JM, MCDOWELL GS, HINDLEY CJ, FIORE-HERICHE CS, KUCEROVA R, HORAN I, PHILPOTT A (2009). Ubiquitylation on canonical and non-canonical sites targets the transcription factor neurogenin for ubiquitin-mediated proteolysis. $J$ Biol Chem 284: 15458-15468.

WEI W, AYAD NG, WAN Y, ZHANG GJ, KIRSCHNER MW, KAELIN WG (2004). Degradation of the SCF component Skp2 in cell-cycle phase $\mathrm{G} 1$ by the anaphasepromoting complex. Nature 428: 194-198.

WILKINSON KD, URBAN MK, HAAS AL (1980). Ubiquitin is the ATP-dependent proteolysis factor I of rabbit reticulocytes. J Biol Chem 255: 7529-7532.

WU T, MERBL Y, HUO Y, GALLOP JL, TZUR A, KIRSCHNER MW (2010). UBE2S drives elongation of $\mathrm{K} 11$-linked ubiquitin chains by the anaphase-promoting complex. Proc Natl Acad Sci USA 107: 1355-1360.

YEW PR, KIRSCHNER MW (1997). Proteolysis and DNA replication: the CDC34 requirement in the Xenopus egg cell cycle. Science 277: 1672-1676.

YOU Z, HARVEY K, KONG L, NEWPORT J (2002). Xic1 degradation in Xenopus egg extracts is coupled to initiation of DNA replication. Genes Dev 16: 1182-1194.

YU H, KING RW, PETERS JM, KIRSCHNER MW (1996). Identification of a novel ubiquitin-conjugating enzyme involved in mitotic cyclin degradation. Curr Biol 6: 455-466.

ZOU H, MCGARRY TJ, BERNAL T, KIRSCHNER MW (1999). Identification of a vertebrate sister-chromatid separation inhibitor involved in transformation and tumorigenesis. Science 285: 418-422.

ZYŁKIEWICZ E, STUKENBERG PT (2014). Xenopus egg extracts as a simplified model system for structure-function studies of dynein regulators. Methods $\mathrm{Mol}$ Biol 1136: 117-133. 


\section{Further Related Reading, published previously in the Int. J. Dev. Biol.}

Control of timing of embryonic M-phase entry and exit is differentially sensitive to CDK1 and PP2A balance Mohammed El Dika, Damian Dudka, Claude Prigent, Jean-Pierre Tassan, Malgorzata Kloc and Jacek Z. Kubiak Int. J. Dev. Biol. (2014) 58: 767-774

Identification of the sperm motility-initiating substance in the newt, Cynops pyrrhogaster, and its possible relationship with the acrosome reaction during internal fertilization

Toshihiko Watanabe, Hideo Kubo, Shinya Takeshima, Mami Nakagawa, Manami Ohta, Saori Kamimura, Eriko Takayama-Watanabe, Akihiko Watanabe, and Kazuo Onitake

Int. J. Dev. Biol. (2010) 54: 591-597

Signalling molecules involved in mouse bladder smooth muscle cellular differentiation

Benchun Liu, Dongxiao Feng, Guiting Lin, Mei Cao, Yuet Wai Kan, Gerald R. Cunha and Laurence S. Baskin

Int. J. Dev. Biol. (2010) 54: 175-180

Nuclear reprogramming in zygotes

Chanchao Lorthongpanich, Davor Solter and Chin Yan Lim

Int. J. Dev. Biol. (2010) 54: 1631-1640

Faithful reprogramming to pluripotency in mammals - what does nuclear transfer teach us?

Julien Maruotti, Alice Jouneau and Jean-Paul Renard

Int. J. Dev. Biol. (2010) 54: 1609-1621

Gonad-stimulating substance-like molecule from the radial nerve of the sea cucumber

Hideki Katow, Tomoko Katow and Akihiko Moriyama

Int. J. Dev. Biol. (2009) 53: 483-491

Cyclin B2/cyclin-dependent kinase1 dissociation precedes CDK1 Thr-161 dephosphorylation upon M-phase promoting factor inactivation in Xenopus laevis cell-free extract

Franck Chesnel, Franck Bazile, Aude Pascal and Jacek Z. Kubiak

Int. J. Dev. Biol. (2007) 51: 297-305

Remodeling of sperm chromatin induced in egg extracts of amphibians.

$\mathrm{C}$ Katagiri and $\mathrm{K}$ Ohsumi

Int. J. Dev. Biol. (1994) 38: 209-216

The influence of mouse sera, regenerating liver extracts and bacterial products on the abilities of different cells in vitro.

N Zarkovic, M Osmak, D Novak, N Lers and M Jurin

Int. J. Dev. Biol. (1991) 35: 239-249

Hormonal factors from the mammalian pineal gland interfere with cell development in Hydra.

W A Müller, C Bartsch, H Bartsch, I Maidonis and E Bayer

Int. J. Dev. Biol. (1998) 42: 821-824
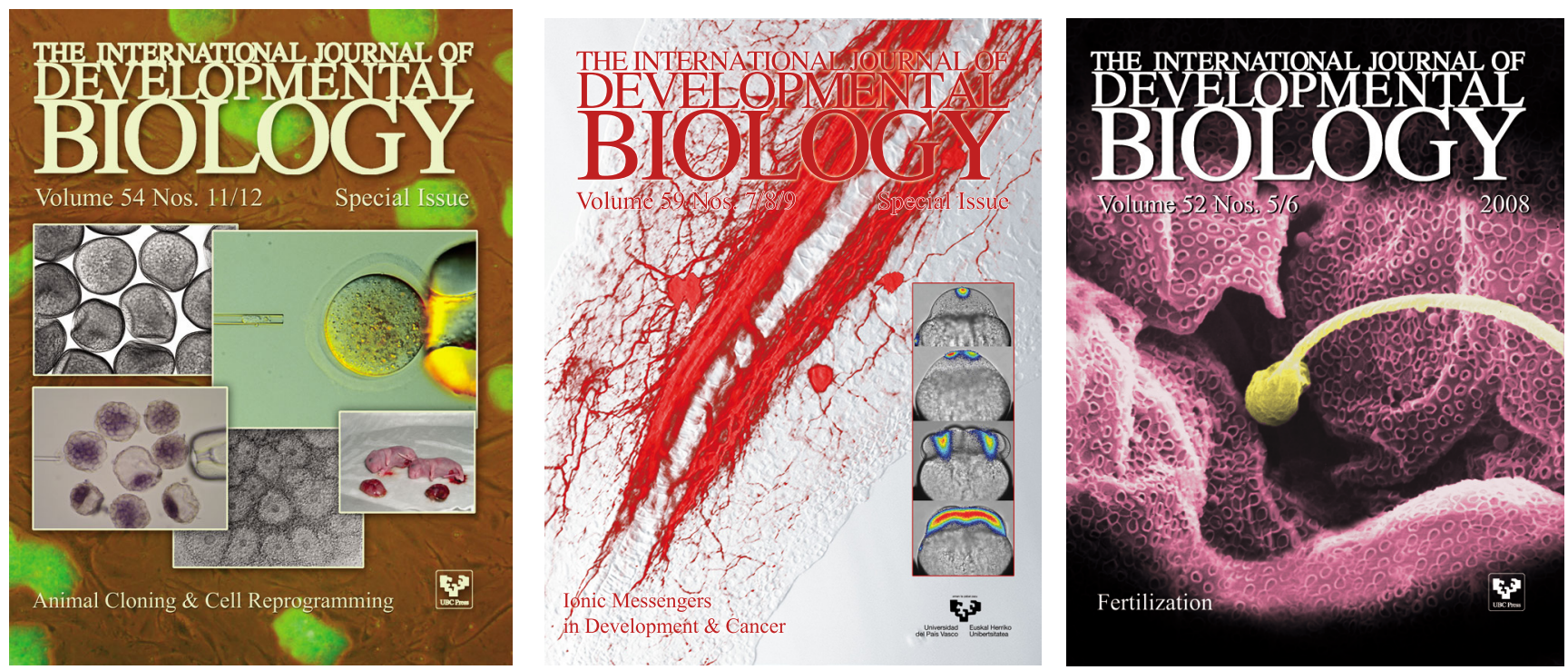